\title{
Impact of Kinesio Taping application on pregnant women suffering from pregnancy-related pelvic girdle pain - preliminary study
}

\author{
Natalia Kuciell ${ }^{1}$ Edyta Sutkowska ${ }^{1}$, Anna Cienska ${ }^{2}$, Dominika Markowska ${ }^{3}$, Zdzisława Wrzosek ${ }^{3}$ \\ ${ }^{1}$ Department and Division of Medical Rehabilitation, Wroclaw Medical University, Poland \\ ${ }^{2}$ Fizis. Functional Rehabilitation, Wroclaw, Poland \\ ${ }^{3}$ University School of Physical Education in Wroclaw, Poland
}

\begin{abstract}
Objectives: The aim of the study was to assess the impact of pregnancy-related pelvic girdle pain on every day functioning and evaluate how effective Kinesio Taping is in reducing pain for pregnant women.

Material and methods: 24 women filled the author's questionnaire, Oswestry Disability Index Questionnaire and Pelvic Girdle Questionnaire before starting the therapy. Elastic tape was applied onto the lumbosacral area for 5 days and was evaluated $1^{\text {st }}$ day of the test immediately before application, day 2, 3, 4, 5, 6 and 10 day of the examination.

Results: ODI score was 20.09 and showed major disability resulting from severity of the pain. PGQ score was 19.909 . Significant pain reduction was registered on the $3^{\text {rd }}$ day after tape was applied, significant pain reduction on the day of tape removal, and 5 days after tape removal.

Conclusions: Elastic tape decreases pain in pregnancy-related pelvic girdle pain. Pelvic girdle pain deteriorates the quality of life for pregnant women.
\end{abstract}

Key words: pregnancy, pelvic girdle pain, disability evaluation, pain management

Ginekologia Polska 2017; 88, 11:620-625

\section{INTRODUCTION}

Pelvic girdle pain in many cases used to be misdiagnosed as low back pain because of the similar nature of ailments: tingling, numbness, subjective feeling of weakness in limbs with reduced functionality, the sense of instability while walking, and radiation of the pain [1]. In addition, the pelvic pain is associated with instability of the lumbosacral complex what is connected with altered laxity and stiffness forces and leads to increased joints translations [2]. Asymmetrical immobilization in the sacroiliac joints is associated with asymmetric muscular tension [3, 4]. Pregnancy-related pelvic girdle pain (PPGP) appears at the end of the 1st trimester and usually lasts until the end of the first month after child delivery. PPGP is most sever between weeks 24 through 36 of pregnancy. The etiology of the problem remains unclear, and it is believed that there are a lot of causes: hormonal, biomechanical, metabolic, genetic or degenerative $[5,6]$. A prior history of similar ailments or trauma of the pelvis increases the risks. The severity of PPGP fluctuates according to a study within the range of 50-60 mm VAS scale (Visual Analogue Scale) [6]. Posture during the occurrence of PPGP is characterized by excessive snap with increased antetorsion of the pelvis while seated or the patients has a "swayback" posture type [3,7]. We can observe the deterioration of coordination (increased rotational amplitudes of pelvis, lumbar segment and thorax), slower gait, followed by increased rotation of the pelvis relative to the chest [8]. Management of the pelvic girdle pain according to journals includes: water gymnastics, bed rest, pelvis stability exercises, avoiding movements which can cause the pain, and acupuncture $[2,5,9-13]$. A single report on the application of: massage therapy, thermothe- 
rapy, mobilization, manipulation, as well as lap belts can be found in the journal referenced [5]. In some cases pain killers like Paracetamol may be used for treatment of women with PPGP, however it is not recommended $[2,14]$.

In the 1970s Dr. Kenzo Kase developed a type of elastic tape applied on the skin which uses the body's natural ability of self-regeneration. The development of new methods and the creation of the Kinesio Taping Association International (1984) has increased the need for research evaluating the effectiveness of taping [15-19]. Kinesio Tex Gold elastic tape is the original Japanese product quality certified by the CE (Conformité Européenne) (National industrial chemical notification and assessment scheme, 1995).

Tape Kinesio Tex Gold consists of cotton and acrylic copolymer. The surface of the tape is not uniform, but interrupted by wave-shaped folds allowing skin contact with the air and protecting against burns. Kinesio Tex Gold directly affects the skin (Ruffinis receptors, pain receptors, deep sensory receptors) and indirectly the lymphatic system, fascia, muscles and ligaments. Acrylic medical glue is activated by heat, and during application it does not seep into the vascular system. It does not have any impact on the fetus. Occasionally, with longer lasting applications (over a week), it can cause skin irritation in susceptible people.

No side effects are observed in the patients using elastic tapes, that is why this modern and non-invasive method is wildly used by practitioners for management of pain. In recent years, Kinesio Taping (KT) physiotherapy method has been used to decrease and prevent pain in women suffering from PPGP due to the effect of increased muscle relaxation while taping is applied $[14,20]$.

\section{OBJECTIVES}

The aim of the study was to assess the impact of PPGP in pregnant women on their everyday functioning and quality of life and the evaluation of the effectiveness of KT method on the subjective feeling of pain in pregnant women suffering from PPGP.

\section{MATERIAL AND METHODS}

Approval of the Medical University Ethics Committee has been obtained (KB-551/2012 of 11/07/2012) before the study.

\section{Patients}

Sixty three pregnant women from Birthing School, suffering from pain in lumbosacral area were recommended to enroll into the study between July and December of 2013. In 39 cases PPGP was diagnosed. Thirty tree patients with this dysfunction agreed to enroll into the study. Four withdrew from the study due to skin irritation (allergic reaction) after application of the tape, five failed to return the questionnaire at the conclusion of the study, three gave birth during the study. Ultimately twenty four patients recruited at the Birthing School were included in the study.

Inclusion criteria:

- age: 20-35 years old;

- $18^{\text {th }}-34^{\text {th }}$ week of pregnancy;

- at least one positive test out of three applied in the diagnoses of PPGP;

- negative Straight Leg Rise test.

Exclusion criteria:

- history of prior pelvic injury;

- skin lesions in the lumbosacral area;

- negative diagnostic tests for pelvic girdle pain and/or positive Straight Leg Rise test;

- chronic pelvic diseases;

- history of allergies to acrylic copolymer.

Included patients were informed about the potential benefits and possible side effects of therapy and the ability to withdraw from the research at any stage. Information concerning the purpose, test, the potential benefits or possible side effects as well as the possibility to withdraw from the research at any time during their lifetime was communicated verbally.

\section{Diagnostic tests}

To assess the nature of the ailment, on the basis of the European Guidelines for Treatment and Diagnostics of PPGP [21] the following diagnostic tests were used:

- Long Dorsal Ligament Test (LDSL) (modified for pregnant women). Test exhibits a sensitivity range of $0.11-0.74$ and is highly specific at levels between $0.76-1.00$ [10, 22, 23];

- Posterior Pelvic Pain Provocation (4P). Its sensitivity range is $0.69-0.93$ with a specificity level of $0.80-0.98$ [23-25];

- Trendelenburg test (modified for pregnant women). The sensitivity range of the modified Trendelenburg test is $0.4-0.62$ with a specificity of $0.99[22,23,26]$;

- Straight Leg Rise test (SLR). The sensitivity of the test is 0.52 with a specificity of 0.89 [27].

The LDLT, 4P and modified Trendelenburg test are specific to pelvic girdle pain. Tests 1 and 2 generated pain in the sacroiliac joints and adjacent soft tissues. 4P test is considered to be the most sensitive and specific test for pain generation in the sacroiliac joints. Modified Trendelenburg test generated pain in the pubic symphysis, which indicates pelvic impairment during load transfer from the trunk to the lower limbs.

SLR test was used to generate pain connected with disc root conflict, and was negative in tested women.

\section{Questionnaires}

Pregnant women filled in the author's own disease questionnaire which has been prepared for the purposes of the study to indicate location of the pain [2]. The result of the 
test-retest reliability within two days was outstanding for all studied questions ( $100 \%$ compliance). Because PPGP is defined based on the topography of the pain [2] participants answered questions about the nature and location of the lumbosacral pain before and during pregnancy.

In addition, patients were asked to fill out standardized questionnaires about: impact of lumbosacral pain during everyday activities: Oswestry Disability Index (ODI) and the characteristics as well as the impact of pregnancy-related pelvic girdle pain during everyday activities: Pelvic Girdle Questionnaire (PGQ).

ODI is a questionnaire about how lower back pain influences quality of life (QoL) and everyday functioning [28, 29]. Pelvic Girdle Questionnaire is designed to assess the quality of life in patients with pelvic girdle pain. The questionnaire is considered sufficiently responsive and representative for the assessment of QoL [6, 30].

\section{Kinesio Taping}

Elastic tapes were applied in areas with the greatest mobility of the thoracolumbar fascia relative to muscles below (Fig. 1).

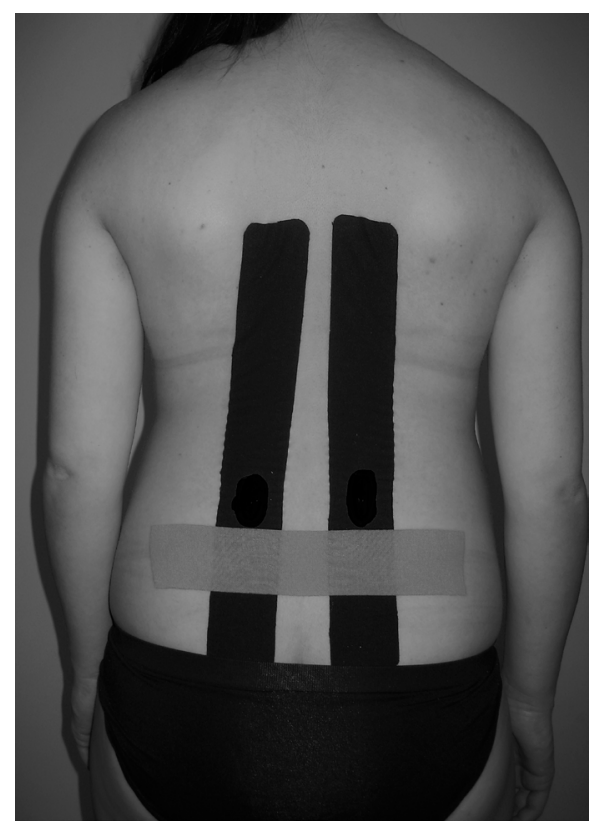

Figure 1. Kinesio Tex Gold applied on the lumbosacral area
Muscular application ( 2 tapes $40 \mathrm{~cm}$ in length) used on both sides of the spine. Distal part of the tape was attached $5 \mathrm{~cm}$ below superior posterior iliac spine, then in the spine flexion when the extensor muscles of the back were stretched, tape, stretched about $10 \%$ of the initial length was attached along the spine on both sides. After spine extending characteristic folds of this application could be observed.

Ligament Application I (one tape $20 \mathrm{~cm}$ in length) applied to the upright trunk. Tape was attached perpendicular to the previous tapes at a height of the sacroiliac joints with stretching 50\% from baseline.

The treatment lasted 5 days. Participants analyzed intensity of the pain and filled out an appropriate survey before the therapy, then in the $2^{\text {nd }}, 3^{\text {rd }}, 4^{\text {th }}, 5^{\text {th }}$ day of the treatment and at $6^{\text {th }}$ and $10^{\text {th }}$ day of the test (days without tape application) $(0,1,2,3,4,5,6$ - days of the assessment during the study respectively) (Fig. 2). Assessment of the pain was made using the VAS scale.

\section{Statistical methods}

Statistical version 12 was used in the analysis of the results. The Shapiro-Wolf test was used to test normal distribution of the results. Depending on the outcome of the analysis of normality, Wilcoxon signet-rang test was used. Differences less than $p=0.05$ were interpreted as statistically significant.

\section{RESULTS \\ Characteristics of participants}

Results of 24 pregnant women were used for statistical analysis.

The mean patients' age was 30.16 years ( $S D \pm 2.79$ ), the mean weeks of pregnancy (HBD): $29.66(S D \pm 4,42)$, the average BMI of patients before pregnancy was 26.49 (SD \pm 14.37 ).

\section{Analysis of the Kinesio Taping efficacy on PPGP based on the VAS score}

Results of the KT method in managing of PPGP are in Table 1.

The average level of pain before tape application was $35.09 \mathrm{~mm}$. A significant reduction of the pain was reported on the $3^{\text {rd }}$ day after tape application and $5^{\text {th }}$ day after application. After tape removal the important reduction in pain

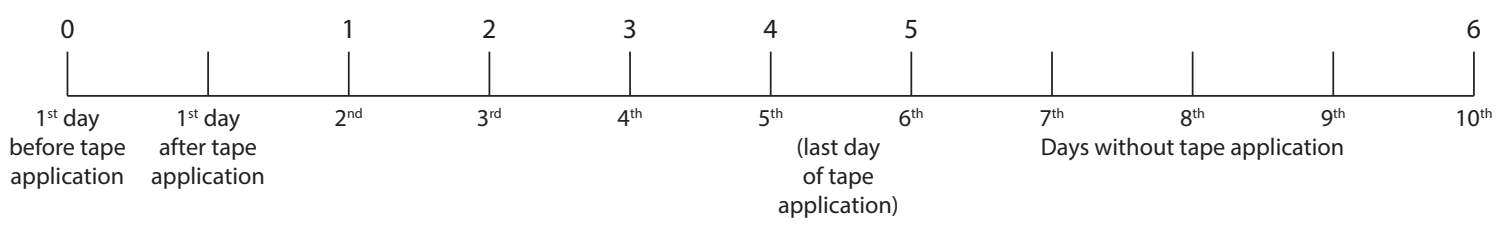

Figure 2. Days of the examination. 0, 1, 2, 3, 4, 5, 6- numbers of the days when VAS was filled 
Table 1. VAS results $(0-100 \mathrm{~mm})$ in each successive days of study

\begin{tabular}{|l|c|c|c|c|c|c|c|}
\hline Day of the therapy when VAS was filled & 0 & 1 & 2 & 3 & 4 \\
\hline Average score VAS [mm] & a & 35.09 & 33.36 & 24.68 & 25.86 & 23.5 & 20.8 \\
\hline Standard deviation [mm] & 28.55 & 26.55 & 22.8 & 27.59 & 26.41 & 23.21 \\
\hline (p) & ( & - & 0.831 & $\mathbf{0 . 0 4 2 4}$ & 0.0800 & $\mathbf{0 . 0 1 2 3}$ & 0.1213 \\
\hline
\end{tabular}

${ }^{a}$ VAS - Visual analogue scale; ${ }^{b}$ statistical significance for each day of the pain assessment during the study contrasted against the first day (assessment before therapy) —Wilcoxon signet-rang test

score was observed in the $10^{\text {th }}$ day of the test (points: 2,4 , 6 in the arrow respectively) (Fig. 2).

\section{Analysis of the impact of PPGP on the quality of life}

ODI score was 20.09 (SD \pm 5.999). Percentage ODI score in the test group was $44.64 \%$ (SD \pm 11.55$)$, reflecting the major disability resulting from the occurrence of pain [29]. Moderate disability was observed in 9 patients (the result of the percentage of ODI was $31.6 \% \mathrm{SD} \pm 5.06$ ), severe disability was observed in 11 patients (the result of the percentage of ODI was $50.19 \%, S D \pm 5.03$ ), crippling back pain has been observed in 2 patients (ODI result was 69.99\%, SD \pm 7.86 ).

The average total PGQ questionnaire result was 19.909 (SD \pm 10.98 ). In terms of percentage result is $28.8 \%$.

\section{DISCUSSION}

Severity of PPGP can be different, as a result of the progress of the disorders and subjective feeling of pain. According to one of the authors reports [5] an average severity of pain in PPGP is 50-60 mm scale VAS. In our study the result was $35 \mathrm{~mm}$ in VAS. Results may vary in studies and could be associated with different factors such as; pregnancy stage, different $\mathrm{BMI}$, age of the pregnant women. Beyond the discomfort and pain, PPGP can also obstruct the performance of the activities of daily living and thus adversely affect the quality of life of pregnant women. In our studies, dysfunction moderately impaired the patient's ability to perform daily activities such as; bending, lifting, sitting, sleeping (according to ODI), housework, long walking, and standing (according to PGQ). Unfortunately, the options for pain therapy in pregnant women are significantly reduced, due to the possible danger to both the mother and the fetus. Most of the standard drugs used effect the fetus and are not recommended, especially for long-term treatment. In the Kaplan study [14] in the experimental group both KT and Paracetamol were used and compared alone to the Paracetamol treatment option in the control group. In the experimental group KT significantly reduced pain when compared to the control group. The main goal of our study was the assessment of whether KT reduces pain in subsequent days of use when compared to the pain assessment before application of KT. If pain reduction was observed it was interesting to see for how long such pain relieve lasted. Based on the results we can state that $\mathrm{KT}$ significantly reduces pain in the studied group of pregnant women and this effect is maintained even after its removal. The tape, acting on skin mechanoreceptors and thoracolumbar fascia, causes relaxation of tense and overloaded tissues, which helps to change the intensity of the pain $[16,18]$. On the basis of the above studies, it is difficult to ascertain why the reduced level of pain was maintained even after cessation of the therapy. It is alleged that elastic tape changes muscle tension and affects body posture but it should be a target for a wider study, with a larger number of patients. KT does not have affect the fetus and has very limited number of side effects that's why it can be used as the first- line therapy in PPGP. In the absence of satisfactory improvement reported by the patient, the practitioner should consider additional therapies. Because of the small number of participants in previous studies it is difficult to choose the best and the most effective tape application in the treatment of pain. In most of the research, the I type muscular application was chosen in the cases of lower back pain $[19,21]$. In Sabbour and Omar studies [20], in patients suffering from lower back pain, Kinesio Taping method was used for a period of 2 weeks, 3 days on followed by a 24 hour break. Efficacy was estimated with use of VAS scale and ODI in two groups (a total of 60 people), where I type muscular application was chosen (along both sides of the spine with a voltage of 15\%) or a ligamental application (perpendicular to the previous) in the pain area. Both applications were considered satisfactory. The usefulness of the method in the treatment of acute pain was evaluated in the study of Hwang Bo and Lee [31] (VAS scale and Oswestry Disability Index), with beneficial effects. Castro-Sanchez et al. [15] also reported reduction in pain feeling, classified according to the VAS scale, and improvement of quality of life but without statistical significance. Pain level tested in our study with use of VAS scale decreased in the 3rd day ( 24 hours after the tape application) and its low level continued throughout the assessment of patients, even in the 10th day of the study ( $5^{\text {th }}$ day after tape removal). Duration of analgesia, and even a progressive decrease of complaints despite the end of the therapy came as a surprise to the researchers. Earlier observations [32] showed that recurrence of the complaints should be expected immediately after removing the tape. It can only be speculated that the use of KT therapy promotes, 
in some cases, restoring the proper muscle tone, and then its maintenance by restoring the correct movement or postural patterns. KT can stop a vicious cycle in which pain forces non-physiological body alignment and causes muscle imbalance and tension. The limitations of the study is a lack of control group with placebo treatment. This comes from the specifics of studied therapy (in this case application of elastic plaster tape). It is not possible to hide the application of the plaster tape from the patient. Because of pregnancy pharmacotherapy was not proposed as an alternative treatment (if not necessary), which is what took place in our study. The women participating in the study did not use pain-control medication before the study and participants did not report such need during intervention as well as during observation time.

Our study was a preliminary one and future observation on a larger sample of participants is needed. Evidence of effectiveness of the KT as noninvasive and low side effect treatment of PPGP in pregnant woman is important for future guidelines.

\section{CONCLUSIONS}

PPGP has negative impact on everyday functioning and quality of life during pregnancy. Elastic tape used in KT method can decrease pain and improve functionality in advanced pregnancy.

\section{Conflict of interest}

None declared.

\section{REFERENCES}

1. Shadmehr A, Jafarian Z, Talebian S. Changes in recruitment of pelvic stabilizer muscles in people with and without sacroiliac joint pain during the active straight-leg-raise test. J Back Musculoskelet Rehabil. 2012; 25(1): 27-32, doi: 10.3233/BMR-2012-0307, indexed in Pubmed: 22398264.

2. Vleeming A, Albert $\mathrm{HB}$, Ostgaard $\mathrm{HC}$, et al. European guidelines for the diagnosis and treatment of pelvic girdle pain. Eur Spine J. 2008; 17(6): 794-819, doi: 10.1007/s00586-008-0602-4, indexed in Pubmed: 18259783.

3. Apte G, Nelson P, Brismée JM, et al. Chronic female pelvic pain — part 1: clinical pathoanatomy and examination of the pelvic region. Pain Pract. 2012; 12(2): 88-110, doi: 10.1111/j.1533-2500.2011.00465.x, indexed in Pubmed: 21615678.

4. Stuge B, Hilde G, Vøllestad N. Physical therapy for pregnancy-related low back and pelvic pain: a systematic review. Acta Obstet Gynecol Scand. 2003; 82(11): 983-990, doi: 10.1034/j.1600-0412.2003.00125.x, indexed in Pubmed: 14616270.

5. Kanakaris NK, Roberts CS, Giannoudis PV. Pregnancy-related pelvic girdle pain: an update. BMC Med. 2011; 9: 15, doi: 10.1186/1741-7015-9-15, indexed in Pubmed: 21324134.

6. Stuge B, Garratt A, Krogstad Jenssen H, et al. The pelvic girdle questionnaire: a condition-specific instrument for assessing activity limitations and symptoms in people with pelvic girdle pain. Phys Ther. 2011; 91(7): 1096-1108, doi: 10.2522/ptj.20100357, indexed in Pubmed: 21596959.

7. Pezolato A, de Vasconcelos $\mathrm{EE}$, Defino $\mathrm{HL}$, et al. Fat infiltration in the lumbar multifidus and erector spinae muscles in subjects with sway-back posture. Eur Spine J. 2012; 21(11): 2158-2164, doi: 10.1007/s00586-0122286-z, indexed in Pubmed: 22465969.

8. Wu WH, Meijer OG, Bruijn SM, et al. Gait in Pregnancy-related Pelvic girdle Pain: amplitudes, timing, and coordination of horizontal trunk rotations. Eur Spine J. 2008; 17(9): 1160-1169, doi: 10.1007/s00586-0080703-0, indexed in Pubmed: 18661160.

9. Elden $\mathrm{H}, \mathrm{Ostgaard} \mathrm{HC}$, Fagevik-Olsen $\mathrm{M}$, et al. Treatments of pelvic girdle pain in pregnant women: adverse effects of standard treatment, acupuncture and stabilising exercises on the pregnancy, mother, delivery and the fetus/neonate. BMC Complement Altern Med. 2008; 8: 34, doi: 10.1186/1472-6882-8-34, indexed in Pubmed: 18582370.

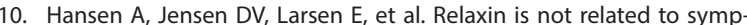
tom-giving pelvic girdle relaxation in pregnant women. Acta Obstet Gynecol Scand. 1996; 75(3): 245-249, doi: 10.3109/00016349609047095, indexed in Pubmed: 8607337.

11. Nilsson-Wikmar L, Holm K, Oijerstedt R, et al. Effect of three different physical therapy treatments on pain and activity in pregnant women with pelvic girdle pain: a randomized clinical trial with 3,6, and 12 months follow-up postpartum. Spine (Phila Pa 1976). 2005; 30(8): 850-856, doi: 10.1097/01.brs.0000158870.68159.d9, indexed in Pubmed: 15834325 .

12. Stanos SP, Mc Le, Rader L. Physical Medicine Rehabilitation Approach to Pain. Med Clin North Am. 2007; 25(4): 725-729.

13. Stuge B, Mørkved S, Dahl HH, et al. Abdominal and pelvic floor muscle function in women with and without long lasting pelvic girdle pain. Man Ther. 2006; 11(4): 287-296, doi: 10.1016/j.math.2005.07.003, indexed in Pubmed: 16386450.

14. Kaplan Ş, Alpayci M, Karaman E, et al. Short-term effects of Kinesio Taping in women with pregnancy-related low back pain: a randomized controlled clinical trial. Med Sci Monit. 2016; 22: 1297-1301, doi: 10.12659/msm.898353, indexed in Pubmed: 27088271.

15. Castro-Sánchez AM, Lara-Palomo IC, Matarán-Peñarrocha GA, et al. Kinesio Taping reduces disability and pain slightly in chronic non-specific low back pain: a randomised trial. J Physiother. 2012; 58(2): 89-95, doi: 10.1016/S1836-9553(12)70088-7, indexed in Pubmed: 22613238.

16. Gramatikova A, Nikolova E, Mitova S. Nature, Application and effect of Kinesio-Taping. Activities Physical Education Sport. 2014; 4(2): 115-119.

17. Kiebzak W, Kowalski I, Pawłowski M, et al. The use of Kinesiology Taping in physiotherapy practice: a systematic review of the literature. Polish J Physiother. 2012; 12(1): 1-11, doi: 10.5604/16420136.990847.

18. Lemos TV, Albino AC, Matheus JP, et al. The effect of kinesio taping in forward bending of the lumbar spine. J Phys Ther Sci. 2014; 26(9): 1371-1375, doi: 10.1589/jpts.26.1371, indexed in Pubmed: 25276018.

19. Added MA, Costa LO, Fukuda TY, et al. Efficacy of adding the Kinesio Taping method to guideline-endorsed conventional physiotherapy in patients with chronic nonspecific low back pain: a randomised controlled trial. BMC Musculoskelet Disord. 2013; 14: 301, doi: 10.1186/14712474-14-301, indexed in Pubmed: 24156687.

20. Sabbour A, Omar H. The Effect of Kinesiotaping Therapy Augmented with Pelvic Tilting Exercises on Low Back Pain in Primigravidas During the Third Trimester. Bull. Fac. Ph. Th. Bull Fac Ph Th Cairo Univ. 2011; 16(1): 53-61.

21. Yoshida A, Kahanov L. The effect of kinesio taping on lower trunk range of motions. Res Sports Med. 2007; 15(2): 103-112, doi: 10.1080/15438620701405206, indexed in Pubmed: 17578750.

22. Albert $H$, Godskesen $M$, Westergaard J. Evaluation of clinical tests used in classification procedures in pregnancy-related pelvic joint pain. Eur Spine J. 2000; 9(2): 161-166, doi: 10.1007/s005860050228, indexed in Pubmed: 10823434.

23. Kristiansson P, Svärdsudd K. Discriminatory power of tests applied in back pain during pregnancy. Spine (Phila Pa 1976). 1996; 21(20): 2337-43; discussion 2343, doi: 10.1097/00007632-199610150-00006, indexed in Pubmed: 8915068.

24. Mens JMA, Vleeming A, Snijders CJ, et al. Reliability and validity of the active straight leg raise test in posterior pelvic pain since pregnancy. Spine (Phila Pa 1976). 2001;26(10): 1167-1171, indexed in Pubmed: 11413432.

25. Ostgaard HC, Zetherström G, Roos-Hansson E. The posterior pelvic pain provocation test in pregnant women. Eur Spine J. 1994; 3(5): 258-260, doi: 10.1007/bf02226575, indexed in Pubmed: 7866847.

26. Wormslev M, Juul AM, Marques B, et al. Clinical examination of pelvic insufficiency during pregnancy. An evaluation of the interobserver variation, the relation between clinical signs and pain and the relation between clinical signs and physical disability. Scand J of Rheumatol. 1994; 23(2): 96-102, indexed in Pubmed: 8165446.

27. Gutke A, Hansson ER, Zetherström $G$, et al. Posterior pelvic pain provocation test is negative in patients with lumbar herniated discs. Eur Spine J. 
2009; 18(7): 1008-1012, doi: 10.1007/s00586-009-1003-z, indexed in Pubmed: 19390876.

28. Barros de, Simoes L, Morelti E, et al. Repercussion of pelvic girdle pain on pregnant women's functionality evaluated through the Brazilian version of the Palvic Girdle Questionnaire (PGQ-Brazil): a cross-sectional study. Fisioter Pesqui. 2015; 22(4): 404-410.

29. Gutke A, Ostgaard HC, Oberg B. Pelvic girdle pain and lumbar pain in pregnancy: a cohort study of the consequences in terms of health and functioning. Spine (Phila Pa 1976). 2006; 31(5): E149-E155, doi: 10.1097/01.brs.0000201259.63363.e1, indexed in Pubmed: 16508539.

30. Hammill RR, Beazell JR, Hart JM. Neuromuscular consequences of low back pain and core dysfunction. Clin Sports Med. 2008; 27(3): 449-62, ix, doi: 10.1016/j.csm.2008.02.005, indexed in Pubmed: 18503877.
31. Hwang-Bo G, Lee JH. Effects of kinesio taping in a physical therapist with acute low back pain due to patient handling: a case report. Int J Occup Med Environ Health. 2011; 24(3): 320-323, doi: 10.2478/s13382-0110029-8, indexed in Pubmed: 21845524.

32. Paoloni M, Bernetti A, Fratocchi G, et al. Kinesio Taping applied to lumbar muscles influences clinical and electromyographic characteristics in chronic low back pain patients. Eur J Phys Rehabil Med. 2011; 47(2): 237-244, indexed in Pubmed: 21430611.

33. Hansen A, Jensen D, Wormslev $M$, et al. Symptom-giving pelvic girdle relaxation in pregnancy, II: Symptoms and clinical signs. Acta Obstet Gynecol Scand. 1999; 78(2): 111-115, doi: 10.1080/j.1600-0412.1999.780207.x, indexed in Pubmed: 10023872. 